\title{
Qualitative Approach Risk Period in Construction Projects
}

\author{
Abdelhak Challal, Mohamed Tkiouat \\ Mohammadia School of Engineering, Studies and Research Laboratory in Applied Mathematics (LERMA) \\ Mohammed V University, Rabat, Morocco \\ Email: challal@daag.finances.gov.ma, mohamedtkiouat@gmail.com
}

Received June $16^{\text {th }}, 2012$; revised July $19^{\text {th }}, 2012$; accepted July $28^{\text {th }}, 2012$

\begin{abstract}
The construction projects have experienced failure in meeting schedule deadlines. This is due to the unanticipated events and factors causing delays. These delays give rise to dissatisfaction to all involved parties; such fact leads to seek identifying delay factors according to their importance level. To achieve this aim, a qualitative analysis of risk is proposed as a decision support tool to achieve project success.
\end{abstract}

Keywords: Project; Construction; Cause Delays; Time; Risk

\section{Introduction}

The problem of delays in the field of construction is a common phenomenon worldwide. In Saudi Arabia, Assaf and AlHejji (2006) found out that only $30 \%$ of construction projects have been completed within the contracted deadlines, and the average slipping period was between $10 \%$ and $30 \%$. In Nigeria, Ajanlekok (1987) identified through a questionnaire survey that the delays have effects on 61 construction projects. The results demonstrated that deadline slippage and cost overruns were frequent and quite significant. The project manager is generally responsible for those causes. Odeyinka and Yusif (1997) also illustrated that 7 projects out of 10 studied had experienced deadline slippage during their execution. Chan and Kumaraswamy (1997) studied the delays in industrial construction in Hong Kong, they underlined the success index of a project and its delivery within the deadlines, respecting the quality norms and the budget allotted to it.

Normally, when we realise that the projects will experience some deadline slippage, we provide a deadline extension or we accelerate the pace of the works execution. As a consequence, we allow for additional expenses, normal practices which generally permit an addition of a supplementary cost percentage based on a prior study (Hatush \& Skitmore, 1997).

Time performance is one of the key measures of the project's success (Hatush \& Skitmore, 1997; Belassi \& Tukel, 1996; Walker, 1995 and 1996).

According to Faridi and El-Sayedgh (Faridi) delays have a negative impact on the success of the project in terms of time, cost, quality and security For Aibium and Jagbor (2002) the entrepreneur and the Project Manager are jointly or separately responsible for the delay in executing construction projects. The delays can not be minimised unless their causes are known, and in order to have an accurate estimate of costs and deadlines, reliable methods and commonly agreed practices must be applied. Faridi and El-Sayedgh also emphasised that these causes must be controlled during the life time of the project. Moreover, an important economy of resources can be obtained while identifying and controlling the causes.

The main objectives of this study are as follows.

- Identifying the causes of delays in construction projects in several regions of Morocco as well as comparing them with those identified by researchers in over the last two decades;

- Ranking the inherent risks in terms of the probability and importance perceived by the participants, such as, the project manager, the clients and the contractors;

- Identifying risks control measures.

This article is organised as follows: section 1 deals with the previous studies on the causes of deadline slippage in construction projects. Section 2 explains the methodology adopted its limitations and acquisitions. Section 3 discusses the results. Section 4 presents the actions and measures which minimise construction project delays Section 5 attempts to draw conclusions and perspectives.

\section{Literature review}

Many articles and studies conducted on the causes of construction project delays worldwide have been examined. Ubaid (1991) concluded in his surveys on the projects completed in Saudi Arabia that lack of entrepreneurial performance is one of the major causes of delays. He also identified the principle measures to reinforce resources and improve entrepreneurial skills. Assaf et al. (1995) Ghafly observed that the major causes linked to construction projects in Saudi Arabia are due to financial problems, changes in project conception, projects' contributions, delay in decisions-taking, getting owners' approval, difficulties in getting a work permit, communication and coordination problems. Chan and Kumaraswamy (1998) have carried out a survey to evaluate the relative importance of 83 factors of potential delays in construction projects in Hong Kong. They observed that 5 major causes of deadline slippage related to mismanagement of risk, bad supervision, condition of the site, delay in taking decisions, varying customer needs, variation of working time. Kaming et al. (1997) has studied the causes of slippage of the completion date of 31 skyscrappers in Indonesia. He noticed that cost overruns happen most frequently and are most significant than deadline slippage. He underlined that the main causes of this slippage are: the increase due to inflation, the underestimate of material cost as well as the degree of complexity of the construction project itself, those relating to slippage are: change of design concep- 
tion, weak productivity, inadequate planning, shortage of resources. Kumaraswamy and Chan noted in a study that the causes in construction projects conducted in Honk Kong were differing perceptions by the different parties. Noulmanee et al. (1999) concluded in a study on the causes of delays in the construction of highways in Tahaland that the major causes are due to sub-contractors' income-petency and poor project conception (incomplete and inaccurate design). They also suggested that the delay could be minimised by devising a good project conception, close coordination and an effective communication among the participants. Al-Momani (2000) in his survey on 130 public projects in Jordan pointed out that the main causes of delay are: poor project conception, climate, poor site management, delay in delivery, economic situation and the amendments. He recommended that managers of public projects take the necessary time to start carrying out thorough studies by using real quantitative data in order to formulate pertinent terms before starting attributing the said project. The study also suggested that special attention be given to industrialists in the field of construction to reduce the purchasing costs. Consequently, the delays are essential due to poor contractors productivity. According to (Koushk et al.; Assaf \& Al-Hajji, 2006; Meeampol \& Ogunlana, 2006), Sambasivan and Soon (2007), Le-Hoai et al. (2008) deadline slippage could lead to a number of negative effects, such as cost overruns Sambasivan and so on, Tow-hid and Amiruddin (2011) noted that major delay consequences are related to: arbitration conflicts, litigations, and total abandonment. Toor and Ogunlana (2008) and Saleh Al Hadi, Tumi et al. (2009) believe that poor planning and lack of communication are the principle causes of deadline slippage in construction projects in Libya. Hamidreza et al. (2010) qualified certain causes as unacceptable in order to respect the contractual deadline for the completion of the construction projects in Hong Kong. These causes are relative to delays of supply and subcontractors' incompetence. M. Haseeb1 et al. (2011) consider that to avoid delays, the project manager must settle the corporate discount on time. Also the enterprise must do the same thing for the subcontractors. Ogunlana et al. (1996) noticed that time and cost overruns in construction projects of sky-scrappers in Bankok and Thailand resulted from three factors: lack of infrastructure, default in payment by both customers and consultants, and contractors incompetency, they recommended that managers and associations specialize in the field of construction, make more efforts to streamline and build the infrastructure which would allow easy supply of materials and boost efficiency in the field of construction. Frimpong et al. (2003) conducted a survey through a questionnaire on underground construction projects in Ghana in order to identify and evaluate the importance related to the factors leading to time and cost overruns of the said projects. The findings revealed that the main causes are: late payment on the part of the project managers, shortage of raw materials, implementation of obsolete construction processes, and the high cost of raw materials. They recommended that to minimise the delays in carrying out the construction works, the projects should be well in advance, and a follow-up should be insured as well as the control and respect of the accomplishment planning.

Over the last decade, researchers have looked into the causes and effects of delays in construction projects and confirm that $51 \%$ of the responsibility lies with the enterprises, followed by the project manager $30 \%$ and the client $19 \%$ and that $90 \%$ of these causes arise from the field and the internal organisation of the intervening parties.

Also the researchers have shown that the causes which occur frequently can be summarised as follows:

- Poor management of the site;

- The company's financial difficulties;

- Modifications made by the employer during the construction phase;

- Delay in plan examination and approval by the project manager;

- Delay in issuing plans.

\section{Methodology}

\section{Overview of Approach}

A construction project is commonly acknowledged as successful when it is completed on time, within budgetary costs and in accordance with the specifications and to participating parties' satisfaction. Being within the deadline of a construction,the project is important after issuing the construction contract, so all concerned involved parties must be able to meet schedule deadlines.

However, when construction industry gets compared to other industries, several interesting facts are to be conveyed, the construction industry is in fact where a combination of various businesses come together, interact and collaborate to complete the project. The intersection of activities and functions make it a difficult task for UCI to identify and determine which one will cause the delay, in fact, in each new project, the UCI have to work each time with new different project team members. Therefore, UCI are found compelled to adapt to such new team and coordinate its members leading them altogether to achieve project success by meeting schedule deadlines.

However, most construction projects are subject to delays because of one actor or more. By the identification of actors causing the delay, the UCI will be allowed to know well before the bidding stage which factor needs to be more emphasized in order to generate a better decision.

This approach is intended to allow the UCI driver to know the important factors causing the delay in building projects. These factors may also be called sources of risk delay in building projects.

The followed method of risk analysis is a qualitative method dedicated to building projects. This analysis allows determining all factors causing the delay. However, the existence of a large number of delay factors doesn't leave to decision maker the possibility to have a clear vision to decide which one to be the most important. Therefore, it becomes his choice to quantify the importance of these factors by the calculation of relative importance index of each factor, all done on the basis of sound expertise of highly skilled experts in building projects. This index serves to quantify each deadline risk in the project delay. These delay factors can't be conceived significant unless they cause a probability of project delay beyond the accepted margin by the clients; it is generally between $20 \%$ and $30 \%$. It is also necessary to be able to quantify the probability of a project delay in case the identified delay factors are not controlled.

Fuzzy logic is also employed here to link causes to effects in order to determine the probability of project delay in case the identified risks are not controlled. 
The stages of this analysis are:

- Identification of factors delaying building projects;

- Ranking of factors delaying building projects using Ishikawa diagrams;

- Quantification of relative importance and ranking of factors according to their importance level;

- Identification of linguistic variables and fuzzy matching functions;

- Codification of input and output variables;

- Construction of fuzzy rules;

- Determination of the weights of fuzzy rules by using the results of the method of relative importance index

- Aggregation and defuzzification results to estimate the probability of delay in the materialisation of risks.

According to the "top-down" process adopted so far by the previous so-called macroscopic studies, and which helped to investigate and assess major risks on the macro-process, through interviews and questionnaires, by starting the evaluation of frequent occurrences, the severity and importance related to the causes by the contractors, the project manager, and the owners. These risks were ranked according to the retained criteria leading to the establishment of a mapping of risk causes

The "top-down" is certainly offering us here an advantage since it makes risk mapping available in a short time.

\section{Assessment Grids}

The grids of reference that help reconcile the requirements are presented as follows:

Grid A.1

A summary of probability and assessment of risks.

\begin{tabular}{cl}
\hline & Probability \\
\hline Level 1 & Rare or very rare \\
Level 2 & Regular/frequent \\
level 3 & Very fréquent to systematic \\
\hline
\end{tabular}

Grid A.2

A summary of assessment of potential risk impact.

\begin{tabular}{cl}
\hline \multicolumn{3}{c}{ Impact } \\
\hline Level 1 & Weak $(0-4)$ \\
Level 2 & Moderate $(4-7)$ \\
Livel 3 & Strong $(7-10)$ \\
\hline
\end{tabular}

Grid A.3

A summary of severity evaluation.

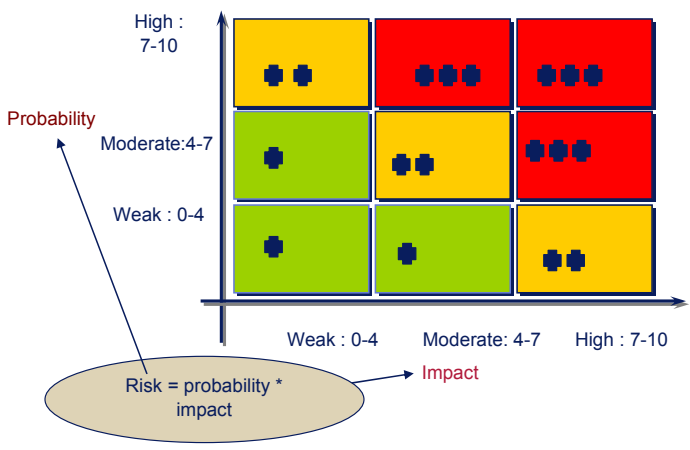

First of all, these elements have been debated with the top management of different participating parties, the actors with the knowledge but lacking a keen interest vis-à-vis risk management. The choice of these people (or what we may also call "casting") turned out to be crucial to the success of the process insofar as we will be led to move from the "project" mode to the "process" mode in the medium-term. Equally the choice of individuals interviewed (who should share their own visions of risks within the enterprise, the project manager, and the owners) was meticulously made.

\section{Research Results}

\section{The General Characteristics of Respondents}

The field survey consisted of 10 entrepreneurs, two owners. The causes of delay were identified after having researches, actions and control measures explored.

\section{Identification and Ranking of Delay Factors in Building Projects}

\section{Identification and Ranking of Delay Factors by Utilizing Ishikawa Diagram}

The Ishikawa Diagram, also known as the Fishbone Diagram or the Cause-and-Effect Diagram, is a tool used for systematically identifying and presenting all the possible causes of a particular effect. The possible causes are presented at various levels of detail in connected branches. The head box of the diagram contains the statement of the problem.

After identifying the factors of delay in the building projects, these factors have been classified in groups of factors, depending on whether they belong to the contractor, the owner or to external factors.

Delay factors related to the project manager identified are 13 in number. They were listed in the Ishikawa diagram in Figure A. Delay factors related to the project manager identified are 13 in number. They were listed in the Ishikawa diagram in Figure A.1. Delay factors related to the project manager identified are 13 in number. They were listed in the Ishikawa diagram in Figure A.1.

\section{Factors Related to Owner}

Delay factors related to the owner have been counted in nine key players. They are listed in the Ishikawa diagram in Figure A.2.

\section{Factors related to the contractor}

Factors related to the contractor have been identified and listed in the Ishikawa diagram in Figure A.3. They are number 20. (Table A.1, Table A.2)

\section{External Factors}

Regarding external factors, 12 main factors have been identified as shown in Figure A.4.

\section{Quantifying the Importance Related to these Factors}

This part aims to quantify the importance related to delays in construction projects. The results of this quantification have 


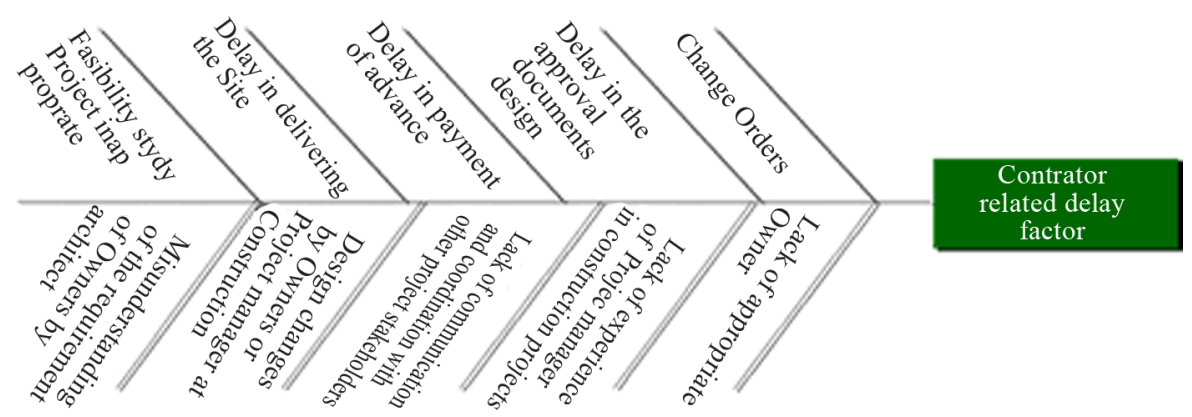

Figure A.1.

Ishikawa Diagram of prime contractor related delay factors.

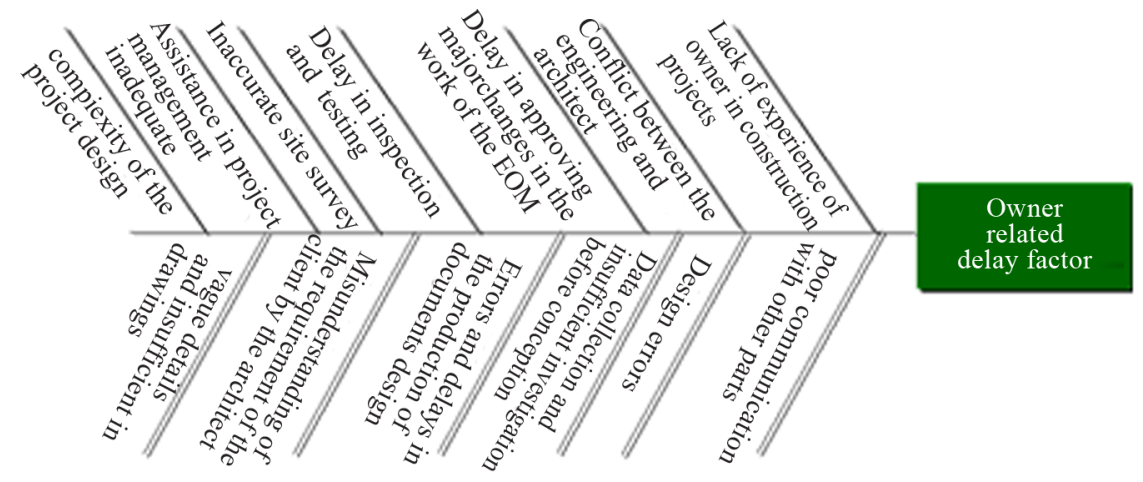

Figure A.2.

Ishikawa Diagram of owner related delay factors.

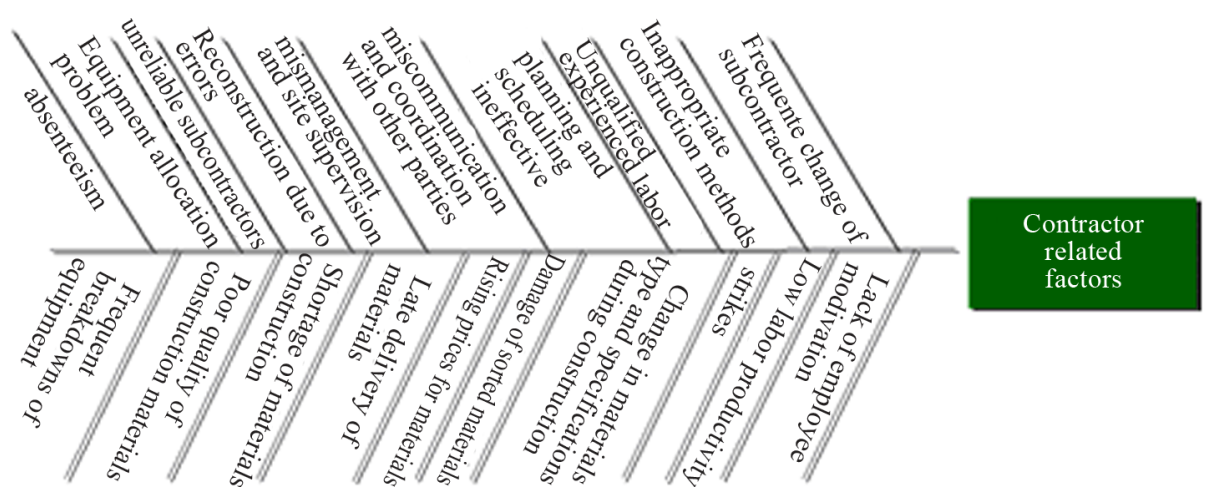

Figure A.3.

Ishikawa Diagram of contractor related delay factors.

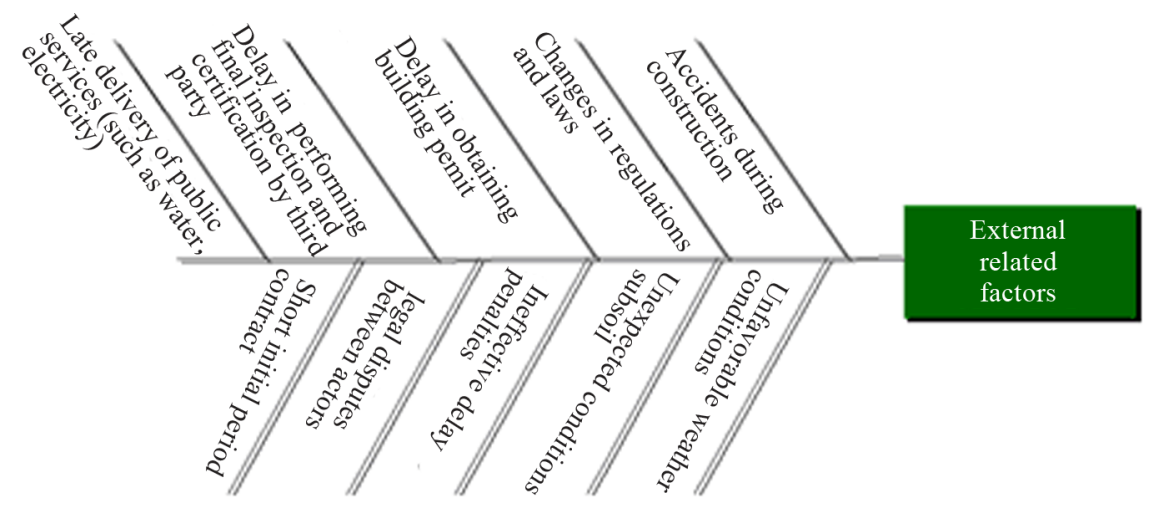

Figure A.4.

Ishikawa Diagram of external related delay factors 
Table A.1.

IIR and ranks of delay factors.

\begin{tabular}{|c|c|c|c|c|c|c|c|c|c|}
\hline \multirow{2}{*}{ Groups of factors } & \multirow{2}{*}{$\mathbf{N}^{\circ}$} & \multirow{2}{*}{ Delay factors } & \multicolumn{5}{|c|}{ Importance } & \multirow{2}{*}{ IIR } & \multirow{2}{*}{ Rank } \\
\hline & & & 1 & 2 & 3 & 4 & 5 & & \\
\hline \multirow{13}{*}{ 1) Owner related factors } & 1 & Lack of experience of the MOE in construction projects & 2 & 1 & 0 & 3 & 4 & 0.72 & 10 \\
\hline & 2 & Conflicts between the office and the architect & 0 & 2 & 4 & 3 & 1 & 0.66 & 12 \\
\hline & 3 & Delay in approving major changes in the work of the EOM & 0 & 0 & 4 & 4 & 2 & 0.76 & 8 \\
\hline & 4 & Delay in inspection and testing & 1 & 1 & 7 & 1 & 0 & 0.56 & 18 \\
\hline & 5 & Inaccurate site survey & 1 & 1 & 6 & 1 & 1 & 0.6 & 16 \\
\hline & 6 & Assistance in project management inadequate & 0 & 1 & 4 & 5 & 0 & 0.68 & 11 \\
\hline & 7 & Poor communication and coordination with other parties & 1 & 0 & 4 & 5 & 0 & 0.66 & 12 \\
\hline & 8 & Complexity of the project design & 0 & 2 & 4 & 2 & 2 & 0.68 & 11 \\
\hline & 9 & Design errors & 1 & 1 & 2 & 0 & 6 & 0.78 & 7 \\
\hline & 10 & Data collection and insufficient investigation before conception & 1 & 0 & 4 & 4 & 1 & 0.68 & 11 \\
\hline & 11 & Errors and delays in the production of design documents & 0 & 0 & 1 & 5 & 4 & 0.86 & 3 \\
\hline & 12 & Misunderstanding of the requirements of the client by the architect & 0 & 0 & 4 & 1 & 5 & 0.82 & 5 \\
\hline & 13 & Inaccurate and insufficient details in the drawings & 1 & 1 & 0 & 3 & 5 & 0.8 & 6 \\
\hline \multirow{9}{*}{ 2) Client related factors } & 1 & Change Orders & 0 & 2 & 5 & 0 & 3 & 0.68 & 12 \\
\hline & 2 & Delay in approving design documents & 0 & 2 & 4 & 0 & 4 & 0.72 & 9 \\
\hline & 3 & Delay in payment of advance & 0 & 0 & 2 & 6 & 2 & 0.8 & 6 \\
\hline & 4 & Delay in delivering the Site & 0 & 1 & 3 & 4 & 2 & 0.74 & 2 \\
\hline & 5 & Feasibility Study Project inappropriate & 0 & 1 & 5 & 2 & 2 & 0.7 & 11 \\
\hline & 6 & Lack of appropriate MOD & 0 & 0 & 2 & 6 & 2 & 0.8 & 6 \\
\hline & 7 & Lack of experience of the client in construction projects & 0 & 0 & 0 & 6 & 4 & 0.88 & 2 \\
\hline & 8 & Lack of communication and coordination with other actors & 1 & 0 & 1 & 6 & 2 & 0.76 & 8 \\
\hline & 9 & Design changes by the MO or MOD during the construction & 0 & 0 & 1 & 3 & 6 & 0.9 & 6 \\
\hline
\end{tabular}

Table A.2.

IIR and ranks of delay factors.

\begin{tabular}{|c|c|c|c|c|c|c|c|c|c|}
\hline \multirow{2}{*}{ Groups of factors } & \multirow{2}{*}{$\mathbf{N}^{\circ}$} & \multirow{2}{*}{ Delay factors } & \multicolumn{5}{|c|}{ Importance } & \multirow{2}{*}{ IIR } & \multirow{2}{*}{ Rank } \\
\hline & & & 1 & 2 & 3 & 4 & 5 & & \\
\hline \multirow{17}{*}{$\begin{array}{l}\text { 3) Contractor related } \\
\text { Factors }\end{array}$} & 1 & Use more subcontractors & 0 & 1 & 0 & 5 & 4 & 0.84 & 4 \\
\hline & 2 & Inappropriate construction methods & 0 & 0 & 2 & 4 & 4 & 0.84 & 4 \\
\hline & 4 & Ineffective planning and scheduling & 0 & 0 & 0 & 5 & 5 & 0.9 & 1 \\
\hline & 5 & Poor communication and coordination with other parties & 0 & 0 & 4 & 5 & 1 & 0.74 & 9 \\
\hline & 6 & Poor management and site supervision & 0 & 0 & 1 & 6 & 3 & 0.84 & 4 \\
\hline & 7 & Reconstruction due to errors & 0 & 0 & 2 & 5 & 3 & 0.82 & 5 \\
\hline & 8 & Unreliable Subcontractors & 1 & 0 & 4 & 2 & 3 & 0.72 & 10 \\
\hline & 9 & Equipment allocation problem & 0 & 2 & 4 & 2 & 2 & 0.68 & 12 \\
\hline & 10 & Frequent breakdowns of equipment & 0 & 1 & 3 & 5 & 1 & 0.72 & 10 \\
\hline & 11 & Absenteeism & 2 & 0 & 1 & 3 & 2 & 0.54 & 19 \\
\hline & 12 & Lack of employee motivation & 1 & 1 & 4 & 3 & 1 & 0.64 & 14 \\
\hline & 13 & Low labor productivity & 0 & 1 & 5 & 2 & 2 & 0.7 & 11 \\
\hline & 14 & Strikes & 2 & 1 & 3 & 3 & 1 & 0.6 & 16 \\
\hline & 15 & Change in type of materials and specifications during construction & 0 & 3 & 3 & 2 & 2 & 0.66 & 13 \\
\hline & 16 & Damage to the materials & 1 & 2 & 4 & 3 & 0 & 0.58 & 17 \\
\hline & 18 & Late delivery of materials & 0 & 2 & 3 & 3 & 2 & 0.7 & 11 \\
\hline & 19 & Shortage of building materials & 0 & 2 & 1 & 5 & 2 & 0.74 & 9 \\
\hline \multirow{13}{*}{$\begin{array}{l}\text { 4) external related } \\
\text { Factors }\end{array}$} & 20 & Poor quality of materials construction & 0 & 1 & 3 & 6 & 0 & 0.7 & 11 \\
\hline & 1 & Accidents during the construction & 2 & 7 & 1 & 0 & 0 & 0.38 & 21 \\
\hline & 2 & Changes in regulations and laws & 4 & 3 & 3 & 0 & 0 & 0.38 & 21 \\
\hline & 3 & Delay in obtaining the permit from the municipality & 0 & 1 & 5 & 2 & 2 & 0.7 & 11 \\
\hline & 4 & Delay in final inspection and certification by the third party & 0 & 3 & 4 & 2 & 1 & 0.62 & 15 \\
\hline & 5 & Delay in the delivery of public services (such as water, electricity) & 0 & 3 & 5 & 1 & 5 & 0.68 & 12 \\
\hline & 6 & Price fluctuations & 1 & 5 & 3 & 0 & 1 & 0.5 & 20 \\
\hline & 7 & unfavorable weather conditions & 0 & 2 & 4 & 1 & 3 & 0.7 & 11 \\
\hline & 8 & Unexpected conditions in the basement & 0 & 1 & 3 & 3 & 3 & 0.76 & 8 \\
\hline & 9 & Ineffective delay penalties & 1 & 2 & 4 & 2 & 1 & 0.6 & 16 \\
\hline & 10 & Legal disputes between the project stakeholders & 1 & 0 & 2 & 1 & 6 & 0.82 & 5 \\
\hline & 11 & Short initial contract term & 0 & 2 & 1 & 1 & 6 & 0.82 & 5 \\
\hline & 12 & Unfavorable contract terms & 1 & 2 & 1 & 2 & 4 & 0.72 & 10 \\
\hline
\end{tabular}


permitted to rank the causes on the basis of their importance level vis-à-vis the project delay.

To count the importance indexes peculiar to each factor, a Likert scale of 5 points has been selected. This scale contains dominance ranging from 1 (very weak importance) to 5 (very high importance).

Likert's scale measures the intensity or the degree of agreement on the part of the respondents which describes a certain phenomenon.

Data analysis method

This scale ranges between 4 and 7 degrees, but Likert's scale is the most widely used with 5 degrees.

This scale is favoured by researchers and seems to be the most widely used because of a number of advantages:

- It easily transforms the feeling on an interval scale which can lead to a statistical analysis;

- It is flexible , and consequently can be used to measure the degree of intensity of a feeling or an attitude;

Data analysis method

The method used to analyse data is the relative importance index method. This index quantifies the relative importance of diverse delay causes following the experts' hindsight judgements. It is calculated as follows:

Equation (A.1): relative importance index.

$$
11 R=\frac{\sum_{1}^{i=A} n_{i} \times i}{A \times N}
$$

$n_{\mathrm{i}}$ : the number of respondents having given an importance of $\mathrm{i}$ to the factor in question

$A$ : the highest importance that is 5 in our case

$N$ : the total number of respondents

This relative importance indices ranges between 0 and $1(0$ excluded). Plus IIR is high, plus this factor contributes largely to project delays.

The choice of the number of experts to be interviewed has been limited to 10 , including architects, contractors, project managers, owners with great experience in construction projects.

\section{Results Analysis}

The relative importance indices has been computed for each factor to identify the most significant delay factor in construction projects.

The following tables transmit the data collected; a rank is attributed to each factor according to its importance index.

Groups and factors that may cause delays in construction projects.

After calculating the IIR of each factor, it becomes possible to calculate the probability of delay of a project in case the deadline risks identified above are not controlled. The values included in IIR reflect one certain persuasion, it is the impact of each factor on the delay of construction project.

The use of fuzzy logic serves to identify relationships between risk sources and their consequences through cause and effect relationships in order to determine the likelihood of project delay.

Fuzzy logic allows representing mental systems (cause to effect relationship, preference degree) in mathematical forms. Bearing in mind that the mental systems enjoys a specificity, it is that they don't abide by the principle of Boolean or classical logic. In fact, in classical or Boolean logic, a variable can't take no more than two values, 1 for "true" and 0 for "false" it is a two-valued logic, in contrast, in fuzzy logic, there is a range of values from "true" to "false". The value may range between completely true and completely false. Thus, a variable can be "somewhat true" with a percentage of $50 \%$ of "true" or "slightly wrong" with a percentage of $25 \%$ of "false".

The definition of membership percentages of the variable to one or the other of states gets one back to define membership functions. These membership functions, also called "fuzzy functions", are used to represent states that can take the variable with the membership percentages in one or the other states.

Fuzzy model as an effective probability analysis technique serves to estimate the delay probability of a project. However, the adopted stages to its development are not controlled; the model inputs are delay factors and also their relative importance while the output is the probability of project delays.

Fuzzy Logic Toolbox ${ }^{\mathrm{TM}}$ de MATLAB ${ }^{\circledR}$ is the tool employed to develop the model.

\section{Using Fuzzy Logic to Estimate the Probability of Delay}

\section{Determination of linguistic Variables and Fuzzy Functions}

The linguistic variables were selected from five variables: "Very low (VL)", "Low (L)", "Medium (M)", "high (H)", "Very high (VH)," in a scale ranges from 0 to 100 . The scale is similar to the 5-point Likert scale described above.

At this point, language assessment factors were transformed to a combination of triangular and trapezoidal functions as shown in Figure A.5.

The operator "Membership Function Editor" of the Fuzzy Logic Toolbox ${ }^{\mathrm{TM}}$ MATLAB $^{\circledR}$ allows the definition of membership functions of inputs and outputs. Figure A.6 shows the input window of the membership functions of input data.

The Figure A.7 shows the input window of the membership functions of output data. These functions are similar to those of the input data.

\section{Consolidation of Input Variables and Output}

To enable linguistic variables to be easily manipulated, a threeletter acronym has been chosen.

An example of this coding is presented in Table A.3.

The codification of the factor groups is as follows:

- Factors related to the supervisor (FME))

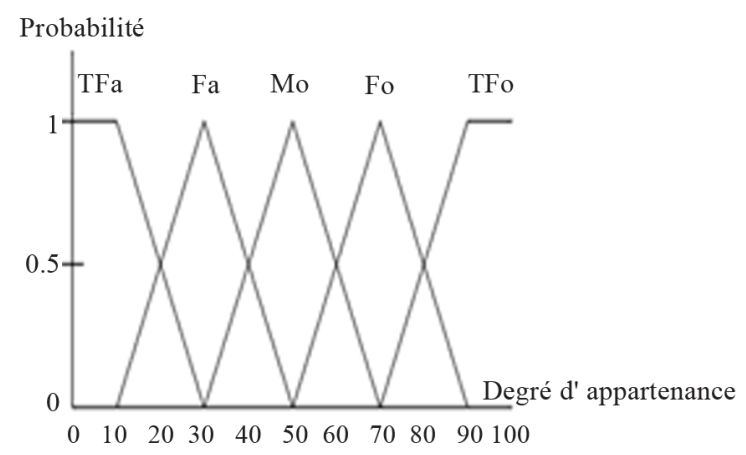

Figure A.5.

Membership functions of linguistic variables. 


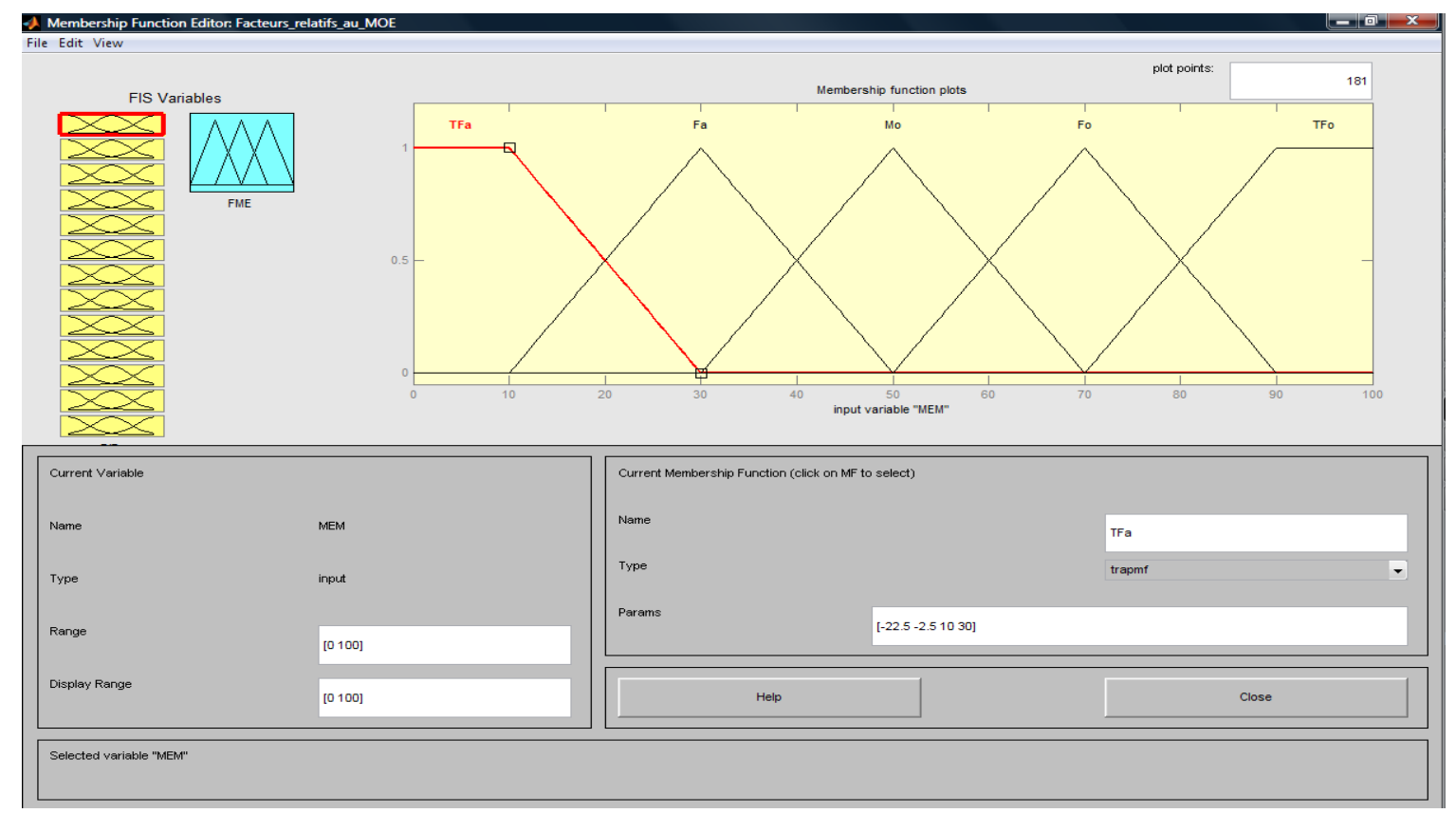

Figure A.6.

Definition of membership functions of inputs.

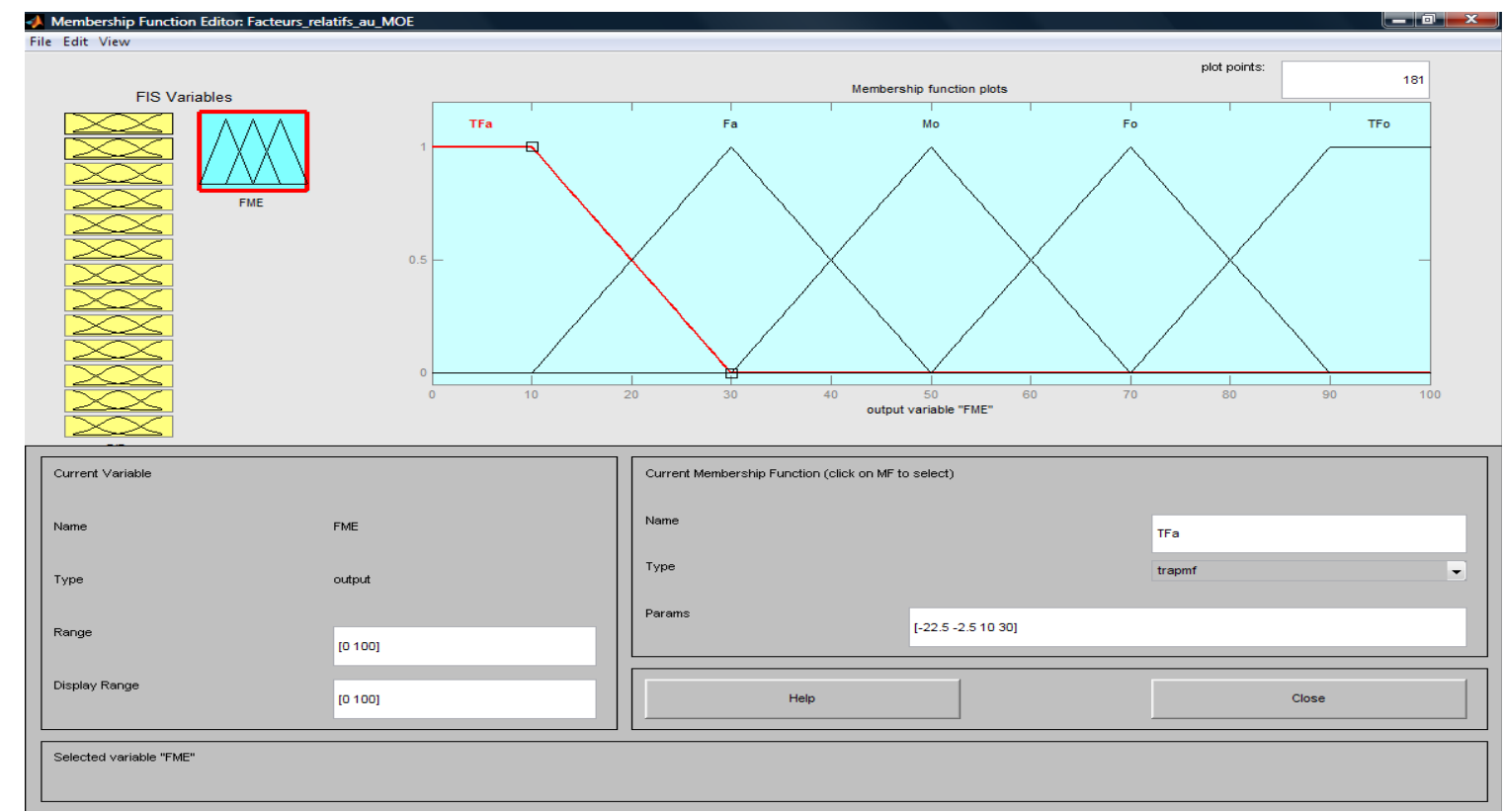

Figure A.7.

Definition of membership functions of output.

Table A.3.

Example of coding delay factors.

\begin{tabular}{lc}
\hline \multicolumn{1}{c}{ Factors } & Acronyms \\
\hline MOE lack of experience in construction projects & MEM \\
Conflicts between the office and the architect & CBA \\
Delay in approval of major changes in the work of the EOM & RAC \\
Delay in inspection and testing & RIE \\
Inaccurate site Inspection & ESI \\
\hline
\end{tabular}

- Factors related to client (FMO)

- Factors relating to the contractor (FEN))

- External Factors (FEX)

\section{Fuzzy Rules and Aggregation \& Defuzzification Rules}

The construction of fuzzy rules has been employed to establish the interrelationships between the input data (the causes of delay) and the output data (the probability of delay overall project) in a natural language format. This form allows the freedom of expressing all delay factors in a simple language. 
In this article, Mamdani approach ("If ... Then") has been implemented, its fuzzy rules have widespread acceptance due to their simplicity, adaptation and for being well suited to human input.

The calculated relative importance indices (IIR) have been assigned as weighs to construct the fuzzy assessment model to estimate the probability delay.

Table A.4: Example the fuzzy rules' weights

After determining fuzzy rules with assigned weights as shown in Figure A.8, it is a must to aggregate and defuzzify results for each group of factors in order to know its contribution to the project delay. The results obtained for each group of factors are, in turn, aggregated and defuzzified the same as the factors in order to reach the overall likelihood of project delays.

The aggregation method has been selected as "max" for being the most popular in the literature. As for the defuzzification, it has been decided to be the Centre Gravity due to the fact that it is the most common adopted method. The result of the aggregation gives a percentage of $71.2 \%$. Therefore, the contribution of the client related delay factor of the project is calculated as $71.2 \%$ as shown in Figure A.9.

The same approach has been adopted for the four groups of delay factor. The following table is used to display the probability that each group of factors contributes to the overall delay of the project.

Aggregation and déffuzification fuzzy rules for the four groups of factors give the probability of overall delay project. The following figure highlights the output window of fuzzy evaluation model, which gives a net outflow representing the probability of delay of a construction project in case identified delay risks materialize. This probability is estimated at $69.1 \%$ as shown in Figure A.10.

\section{Interpretation of Results}

The probability of delay of a construction project including possible and uncontrolled risks has been estimated at $69.1 \%$. (Table A.5, Figure A.10)

The group of factors related to owner has the greatest likelihood of contributing to the delay $(\mathrm{Pr}=78 \%)$ this is due in particular to "design changes by the client or the client representative at construction" ( $\mathrm{RII}=0.9)$, the "lack of experience of the client in construction projects" (RII $=0.88)$ and lack of communication and coordination with other project stakeholders $(\mathrm{IIR}=0.76)$.

The second largest group is that factors related to the contractor $(\mathrm{Pr}=72.4 \%)$. Factors that contributed most are "ineffective planning and scheduling" ( $\mathrm{RII}=0.9)$, "poor site management and supervision" (RII $=0.84)$ and "inappropriate construction methods" (IIR $=0.84)$.

The group of factors related to the supervisor ranks third ( $\mathrm{Pr}$ $=71.2 \%$ ). Factors that have contributed most are "errors and delays in the production of design documents" $(\mathrm{RII}=0.86)$, "vague and inadequate details in the drawings" $(\mathrm{RII}=0.82)$ and "misunderstanding requirements of the client by the architect" $(\mathrm{RII}=0.8)$.

The group of external factors ranked last $(\operatorname{Pr}=62.7 \%)$. The most important factors in this group are "legal disputes between project stakeholders" $(\mathrm{RII}=0.82)$, "short initial contract term" $(\mathrm{RII}=0.82)$ and "unexpected conditions in the basement" (RII $=0.76$ ).

Since experts estimate that building projects likely to delay a project of between $20 \%$ and $30 \%$ is acceptable, the probability obtained, which is $69.1 \%$, is largely unacceptable. It is therefore essential to take steps to respond to the identified risks.

Table A.4.

An example of Assigning Weights to the Fuzzy Rules presented in.

\begin{tabular}{|c|c|c|c|c|c|c|c|c|c|}
\hline \multirow{2}{*}{$\begin{array}{c}\text { Rule } \\
1\end{array}$} & \multicolumn{4}{|c|}{ Probability of delay rules } & \multicolumn{4}{|c|}{ Consequence } & \multirow{2}{*}{$\begin{array}{c}\text { Rules weight } \\
0.72\end{array}$} \\
\hline & If & MEM & Is & TFo & Then & FME & Is & TFo & \\
\hline 2 & If & CBA & Is & Fo & Then & FME & Is & Fo & 0.66 \\
\hline 3 & If & RAC & Is & Mo & Then & FME & Is & Mo & 0.76 \\
\hline 4 & If & RIE & Is & $\mathrm{Fa}$ & Then & FME & Is & $\mathrm{Fa}$ & 0.56 \\
\hline 5 & If & ESI & Is & $\mathrm{TFa}$ & Then & FME & Is & $\mathrm{TFa}$ & 0.6 \\
\hline
\end{tabular}

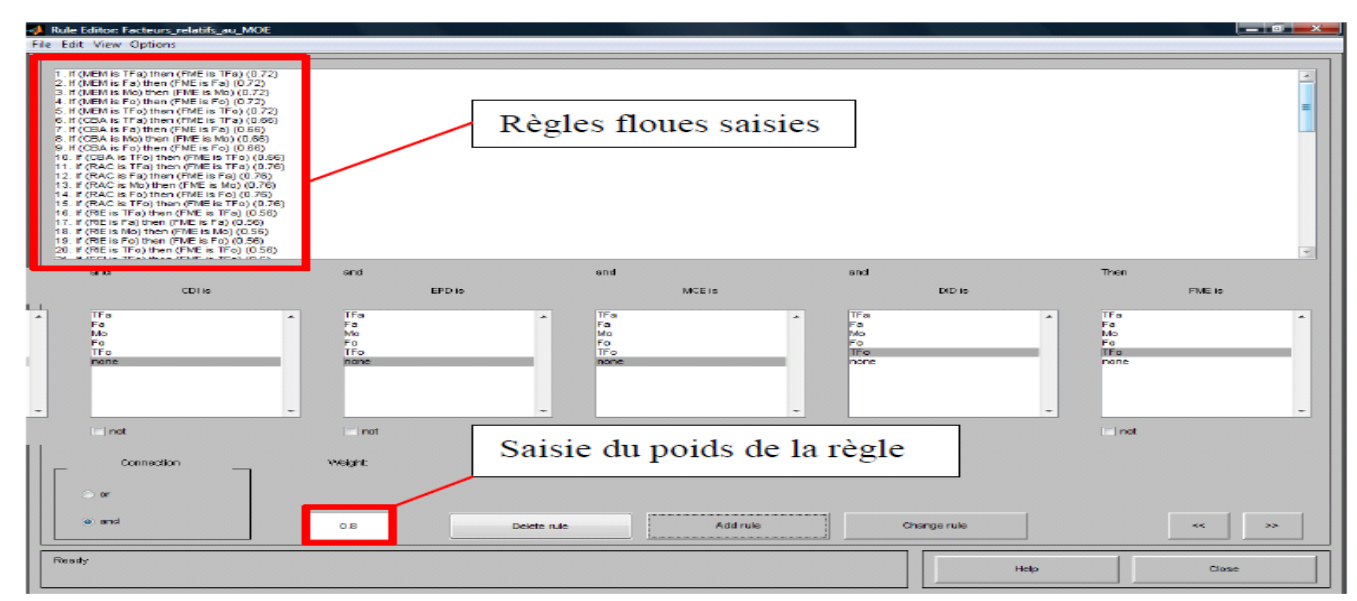

Figure A.8.

Entry Window fuzzy rules of the operator "Rule Editor". 


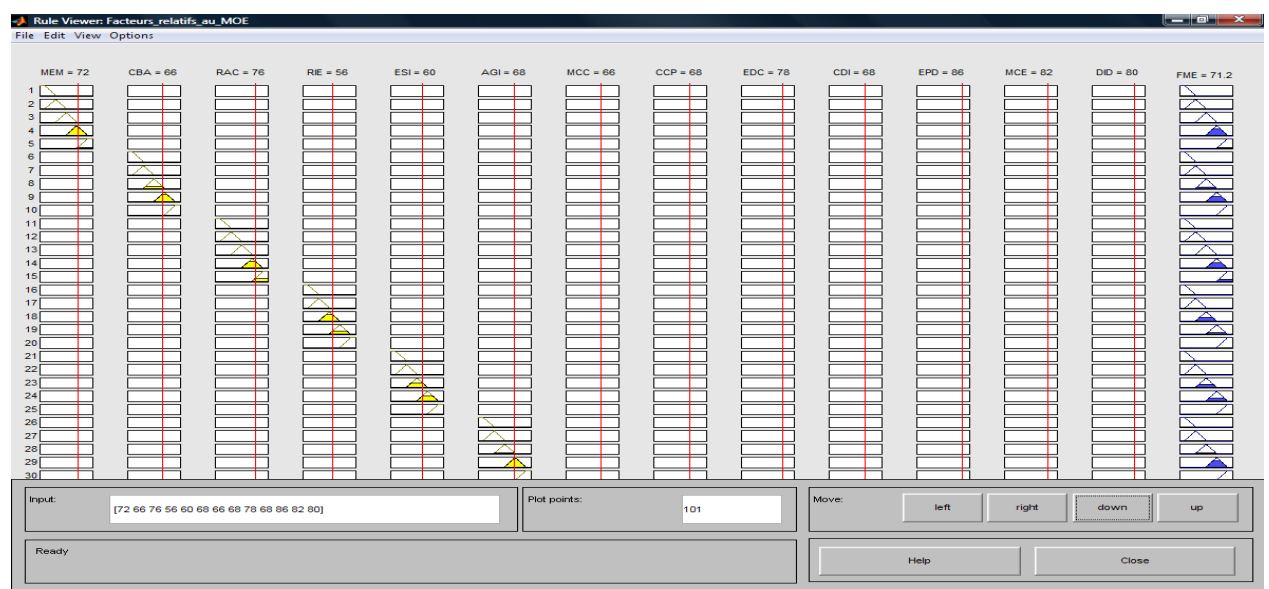

Figure A.9.

Viewing results on the operator "Rule Viewer".

Table A5.

Relative importance Indices of groups of factors.

\begin{tabular}{lcc}
\hline \multicolumn{1}{c}{ Groups of factors } & Probability of contributing factor in the delay of the project (Pr) & Rang \\
\hline Prime contractor related factors & 0.712 & 3 \\
Client related factors & 0.780 & 1 \\
The contractor related factors & 0.724 & 2 \\
External related factors & 0.627 & 4 \\
\hline
\end{tabular}

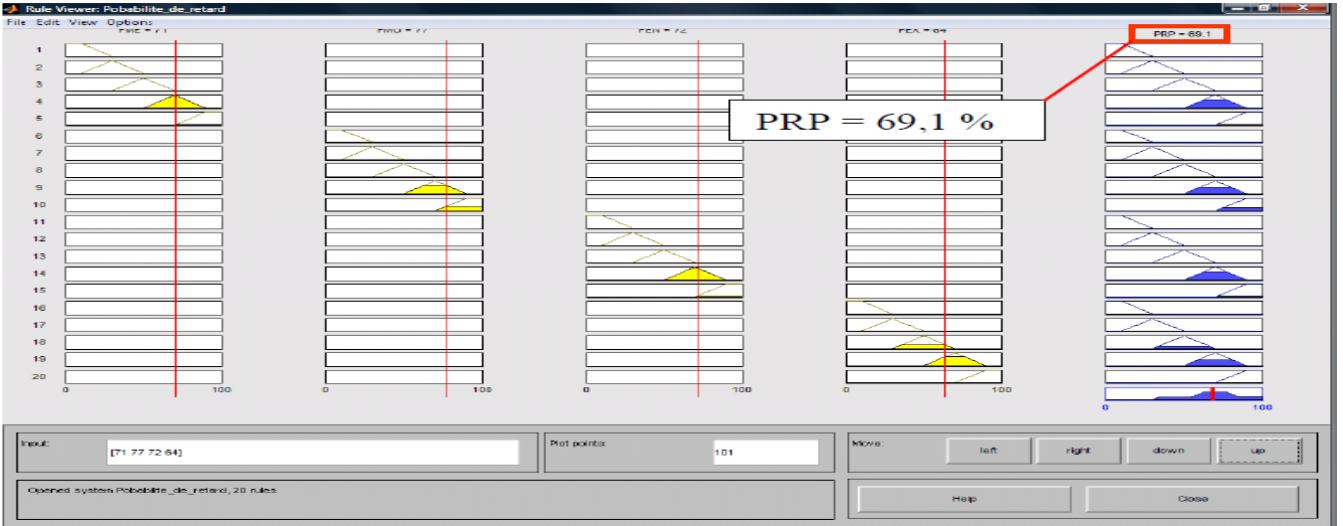

Figure A.10.

Result on four groups of factors.

\section{Recommendations and Action Plan}

\section{Development of Responses to Risks Identified and Action Plan}

This section aims to present the proposed strategies for each risk identified, to justify the choice of type of response, and to suggest remedial actions.

The following table represents the answer key to main risks identified following qualitative analysis. This grid displays the label of risk, its relative importance index, rank, the risk response strategy and the proposed action for the implementation of the response strategy.

\section{Conclusion}

This paper aims to shed light on the importance of delay risks in the preliminary stages of a building project. The state of uncertainty due to poor estimate of tasks duration of building projects has been explained by the identification of delay factors, these factors have also been ranked according to their importance level. Then, certain actions have been developed as a respond to the risks of delay followed by technical proposals to control and monitor those risks.

Finally, a decision support tool has been proposed as a process in managing the risk of delay with the intention of making it a part of the global project management process.

Every new project presents new situations that require special treatments to be coped with. Thus, the risk register must be kept updated by the UCI supported by the experience gained through previous projects. The new identified risks are to be met with risk responses as well as monitoring and controlling plans. 


\section{REFERENCES}

Afshari, H., Khosravi, S., Ghorbanali, A., Borzabadi, M., \& Valipour, M. (2010). Identification of causes of non-excusable delays of construction projects. International Conference on E-Business Management and Economics, International Economics Development and Reseach Center, Hong Kong, 42-46.

Ajanlekoko, J. O. (1987). Controlling cost in the construction industry. Lagos QS Digest, 1, 8-12.

Albinu, A. A., \& Jagboro, G. O. (2002). The effects of construction delays on project delivery in Nigerian construction industry. International Journal of Project Management, 20, 593-599. doi:10.1016/S0263-7863(02)00028-5

Al-Momani, A. H. (2000). Construction delay: A quantitative analysis. International Journal of Project Management, 18, 51-59. doi:10.1016/S0263-7863(98)00060-X

Assaf, S. A., \& Al-Hejji, S. (2006). Causes of delay in large construction projects. International Journal of Project Management, 24, 349357. doi:10.1016/j.ijproman.2005.11.010

Assaf, S. A., Al-Khalil, M., \& Al-Hazmi, M. (1995). Causes of delays in large building construction projects. Journal of Management in Engineering, 11, 45-50. doi:10.1061/(ASCE)0742-597X(1995)11:2(45)

Belassi, W., \& Tukel, O. I. (1996). A new framework for determining critical success/failure factors in projects. International Journal of Project Management, 14, 141-151. doi:10.1016/0263-7863(95)00064-X

Chan, D. W., \& Kumaraswamy, M. M. (1997). A comparative study of causes of time overruns in Hong Kong construction projects. International Journal of Project Management, 15, 55-63. doi:10.1016/S0263-7863(96)00039-7

Faridi, A. S., \& El-Sayegh, S. M. (2006). Significant factors causing delay in the UAE construction industry. Construction Management and Economics, 24, 1167-1176. doi:10.1080/01446190600827033

Frimponga, Y., Oluwoyeb, J., \& Crawfordc, L. (2003). Causes of delay and cost overruns in construction of ground-water projects in a developing countries, Ghana as a case study. International Journal of Project Management, 21, 321-326. doi:10.1016/S0263-7863(02)00055-8

Haseeb, M., Lu, X. H., Bibi, A., Maloof-ud-Dyian, \& Rabbani, W. (2011). Causes and Effects of delays in large construction projects of Pakistan. Kuwait Chapter of Arabian Journal of Business and Management Review, 1, 18-42.

Hatush, Z., \& Skitmore, M. (1997). Evaluating contractor pre-qualification data: Selection criteria and project success factors. Construction Management and Economics, 15, 129-147. doi:10.1080/01446199700000002

Kaming, P., Olomolaiye, P., Holt, G., \& Harris, F. (1997). Factors influencing construction time and cost overruns on high-rise projects in
Indonesia. Construction Manage- ment and Economics, 15, 83-94. doi:10.1080/014461997373132

Koushk, P. A., AL-Rashid, A. K., \& Kartam, N. (2005). Delays and cost increases in the construction of private residential projects in Kuwait. Construction Management and Economics, 23, 285-294.

Kumaraswamy, M., \& Chan, D. (1998). Contributors to construction delay. Construction Management and Economics, 16, 17-29. doi:10.1080/014461998372556

Le-Hoai, L., Lee, Y. D., \& Lee, J. Y. (2008). Delay and cost overruns in Vietnam large construction projects: A comparison with other selected countries. Journal of Civil Engineering, 12, 367-377.

Meeampol, S., \& Ogunlana, S. O. (2006). Factors affecting cost and time performance on highway construction projects: Evidence from Thailand. Journal of Financial Management of Property and Construction, 11, 3-20.

Noulmanee, A., Wachirathamrojn, J., Tantichattanont, P., \& Sittivijan, P. (1999). Internal causes of delays in highway construction projects in Thailand. www.ait.clet.com.

Odeyinka, H. A., \& Yusif, A. (1997). The causes and effects of construction delays on completion cost of housing projects in Nigeria. Journal of Financial Management of Property and Construction, 2, 31-44.

Ogunlana, S. O., Promkuntong, K., \& Jearkjirm, V. (1996). Construction delays in a fast-growing economy: Comparing Thailand with other economies. International Journal of Project Management, 14, 37-45. doi:10.1016/0263-7863(95)00052-6

Pourrostam, T., \& Ismail, A. (2011). Significant factors causing and effects of delay in Iranian construction projects. Australian Journal of Basic and Applied Sciences, 5, 450-456.

Sambasivan, M., \& Soon, Y. W. (2007). Causes and effects of delays in Malaysian construction industry. International Journal of Project Management, 25, 517- 526. doi:10.1016/j.ijproman.2006.11.007

Toor, S. U. R., \& Ogunlana, S. O. (2008). Problems causing delay in major construction projects in Thailand. Construction Management and Economics, 26, 395-408. doi:10.1080/01446190801905406

Tumi, S. Al H., Omran, A., \& Pakir, A. H. K. (2009). Causes of delay in construction industry in Libya. The International Conference on Economics and Administration, Faculty of Administration and Business, University of Bucharest, Romania, 265-272.

Ubaid, A. G. (1991). Factors affecting contractor performance. Master's Thesis, Dhahran: King Fahd University of Petroleum and Minerals.

Walker, D. H. T. (1995). An investigation into construction time performance. Construction Management and Economics, 13, 263-274. doi: 10.1080/01446199500000030

Walker, D. H. T. (1996). The contribution of the construction management team to good construction time performance-An Australian experience. Journal of Construction Procurement, 2, 4-18. 